\title{
New and little-known beetles of Central, South Africa and Reunion Island (Coleoptera: Cryptophagidae)
}

\section{Новые и малоизвестные жкуки Џентральной, Южкной Африки и о.Реюньон (Coleoptera: Cryptophagidae)}

\author{
G.Yu. Lyubarsky \\ Г.Ю. Аюбарский
}

Zoological Museum of Moscow State University, Bol’shaya Nikitskaya str. 2, Moscow 125009, Russia.
Зоологический музей МГУ, ул. Б. Никитская 2, Москва 125009, Россия.

KEY WORDS. Coleoptera, Cryptophagidae, Erotylidae, Reunion, KwaZulu Natal, South African Republic. КЛЮЧЕВЫЕ СЛОВА. Coleoptera, Cryptophagidae, Erotylidae, Реюньон, Квазулу-Натал, ЮАР.

ABSTRACT. The material from Rwanda, KwaZulu Natal, and Reunion has been studied. A few species of Cryptophagus, Micrambe, Henoticus, Atomaria, and Curelius are determined. Micrambe zuluensis sp.n. is described. A key to Micrambe species with double pubescence from S. Africa is presented. A male specimen was found of Micrambe hanstroemi, its aedeagus and paramere are pictured. Several species are designated as new to Rwanda.

РЕЗЮМЕ. Изучен материал из Руанды, Наталя и о. Реюньон. Указаны виды родов Cryptophagus, Micrambe, Henoticus, Atomaria, Curelius. Описан новый вид Micrambe zuluensis sp.n. Приведён ключ южноафриканских видов Micrambe с двойным опушением. Найден самец Micrambe hanstroemi, приведено изображение эдеагуса и парамер. Несколько видов отмечены как новые для Руанды.

\section{Introduction}

Earlier, based on the study of African material, works were published describing the fauna and the new species [Lyubarsky, 2011, 2013]. The present work continues the description of South African material from the collection of the Zoological Museum of Moscow State University (ZMMU).

Recently, material consisting of small beetles of several families was collected on the island of Reunion by Dr. J. Poussereau. Among these small beetles were members of the families Cryptophagidae, Erotylidae, Phalacridae, Endomychidae, Nitidulidae, Latridiidae, Salpingidae, Histeridae, Hydrophilidae, Scolytidae, and Tenebrionidae. Beetles of the first three families have been identified to species. The following is material from Reunion Island of zoogeographic interest. In addition, the collection of the Zoological Museum of Moscow State University contains materials on Cryptophagidae from the Kwa-Zulu National Park (Pietermaritzburg) (collected by M. Mostovski) and from Rwanda (collected by S. Kurbatov). Partially material from KwaZulu has already been reviewed [Lyubarsky, 2011]. An earlier article described the fauna of Reunion Island on the families Cryptophagidae and Erotylidae [Lyubarsky, 2013]. The results of the study of mainly new African material are presented in this article.

An article by Lyubarsky [2011] describes the material from KwaZulu Natal and indicates an indefinite species of Micrambe. Thanks to the review by Otero [Otero, 2005, 2012; Otero, Pereira, 2017, 2018, 2019], it was possible to indicate the status of the new species.

While the materials from Pietermaritzburg were collected on the territory of Hilton, the material from Rwanda is entirely collected using pheromone traps for bark beetles. Therefore, precise linkage to the biotope for the beetles from Rwanda is difficult. Traps placed on the Karamba trail were set in the forest around a large, long-fallen tree. Traps placed on the Kamiranzovu trail were set in a forest in a swampy area among a young growth of trees without nearby trunks. Traps were set in the shadow. By the time of collecting, it was already a month and a half since the rainy season ended, therefore it was relatively dry in the forest, but in some places the litter still remains wet.

Material is stored in ZMUM and in a collection of $\mathrm{J}$. Poussereau.

How to cite this article: Lyubarsky G.Yu. 2019. New and little-known beetles of Central, South Africa and Reunion Island (Coleoptera: Cryptophagidae) // Russian Entomol. J. Vol.28. No.4. P.377-382. doi: 10.15298/ rusentj.28.4.06 


\section{Taxonomical part}

Cryptophagidae Kirby, 1826

Micrambe C.G. Thomson, 1863

Micrambe reunionensis Lyubarsky, 2013

MATERIAL. La Reunion, 974, Piton Bebour, 1400 m, malaise, 02.01.2011, coll. Th. Ramage, (6 spec.); La Reunion, 974, TroisBassins, $1500 \mathrm{~m}$, piege lumineux, 07.01.2013, leg. J. Poussereau, (7 spec.); La Reunion, 974, La Roche-Ecrite, $2000 \mathrm{~m}$, battage 28.08.2003, leg. J. Poussereau, (1 spec.); Reunion, 974, ND de la pais, $1700 \mathrm{~m}$, polypore, 17.02.2013, leg. J. Poussereau, (1 spec.); La Reunion, 974, ND de la paix $1700 \mathrm{~m}$, Sentier marmailles polypore, 05.02.2013, leg. J. Poussereau, (1 spec.); La Reunion, 974, Petite ile Ft de bel air battage 24.11.2004, leg. J. Poussereau, (1 spec.); La Reunion, 974, Notre dame de la paix, Prairie Lebihan, $1700 \mathrm{~m}$, Fauchage graminees, 27.12.2016, leg. J. Poussereau, (4 spec.); Reunion, Saint-Pierre, C.I.R.A.D., leg. J. Poussereau (9 spec.) Material stored in collection of J. Poussereau.

REMARKS. On Reunion, a large amount of, apparently, the background species of this genus on the island is found.

DISTRIBUTION. La Reunion.

\section{Micrambe hanstroemi (Bruce, 1957)}

Figs 1-2.

MATERIAL. S. Africa: RSA, Kwa-Zulu Natal, Roval Nata NR, Mahai camp, 28.688oS 28.948oE, 1450 m, Yellow Pan Trap, 24.11-06.12.2005, leg. M. Mostovski, $10^{7}$.

REMARKS. The revision of Otero [2012: 420] states "male: unknown". Thus, the first male specimen of this species

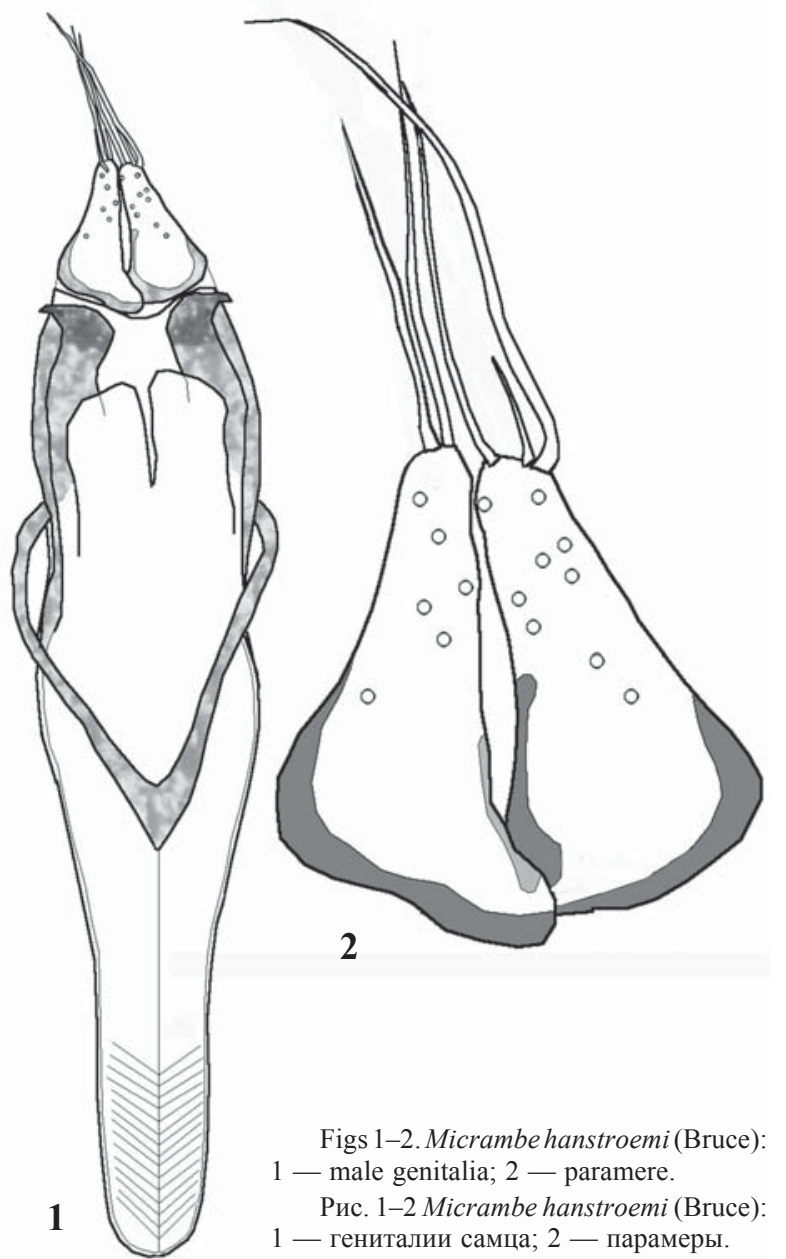

was found. Type finding: Typus ${ }^{\circ}$ : South Africa. KwazuluNatal, Royal Natal National Park; Gudu Falls, [28³2'S 30 53'E], 4.IV.1951. N ${ }^{\circ}$ 260. Swedish South Africa Expedition 1950-1951. Thus, the male was found in the same national park as the type specimen. In the first male described, the hind tarsi are 5-segmented. This is an important character: tarsal formula 5-5-5 in both sexes. In the double-pubescence Micrambe group of South Africa, this character is found only in $M$. endroedyi (Otero, 2005). Unfortunately, in Otero [Otero, 2005], this species was described with errors: in the figure, the male has 4-segmented hind tarsi, although the description says that the tarsi of both sexes are 5-segmented. The general view of the aedeagus and parameres in $M$. endroedyi Otero [Otero, 2005: fig. 7] and M. hanstroemi (this paper, Fig. 2) is very similar, but in the species $M$. endroedyi at the top of the parameres there are 3 long chetae, and $M$. hanstroemi has 2 long chetae. In the key of the species on pages 435-436, Otero [2012] distinguishes these species mainly by indicating the difference in the structure of the tarsi (not confirmed) and the difference in the transversity of the pronotum: strongly transverse in $M$. endroedyi and very slightly transverse in M. hanstroemi.

In the subfamily Cryptophaginae, males usually have tarsi 554, and females 555. This character of males appeared in the Cretaceous [Lyubarsky, 2015]. This pattern is maintained in various regions, but in Africa, in the genera Micrambe and Henoticus, males lose this character and have legs 555, as in females. This loss of the character of males occurs in different genera independently and apparently happened several times, because not all species possess this character of indistinguishability of the tarsi of females and males, and the species in question do not form a separate grouping.

DISTRIBUTION. South Africa: RSA: Kwa-Zulu Natal.

\section{Micrambe natalensis (Bruce, 1952)}

MATERIAL. S. Africa: RSA, Kwa-Zulu Natal, Pietermaritzburg, Hilton, Malaise trap, 23.10-12.11.2003, leg. M. Mostovski, $10^{7} 1$; the same data, 24.12.2003-14.01.2004, leg. M. Mostovski, $3 \sigma^{7}$; the same data, 27.01-16.02.2004, leg. M. Mostovski, 507 11; the same data, 17-29.02.2004, leg. M. Mostovski, 207, 12우 data, 29.02-13.03.2004, leg. M. Mostovski, $7 \sigma^{7} 8$; the same data, 3-5.03.2004, leg. M. Mostovski, $1 \sigma^{\top} 1$ 웅

DISTRIBUTION. RSA: Kwazulu-Natal, Cape Province, Mpumalanga, Northern Cape, Western Cape; Zambia, Zimbabwe, Angola.

\section{Micrambe nigerrima Bruce, 1952}

MATERIAL. E.Africa: SW Rwanda: Nyungwe Nat.Park, 18002000 m, 3-16.07.2014, leg. S. Kurbatov, $10^{7}$.

DISTRIBUTION. Ñ.Africa: DR Congo, Rwanda. New for Rwanda.

\section{Micrambe plagiata Grouvelle, 1908}

MATERIAL. S. Africa: RSA, Kwa-Zulu Natal, Pietermaritzburg, Hilton, Malaise trap, 29.02-13.03.2004, leg. M. Mostovski, $1 \sigma^{7}$.

DISTRIBUTION. RSA: Kwazulu-Natal and Cape Province (Cape Peninsula and Namaland); Eastern Cape, Northern Cape and Western Cape.

\section{Micrambe sp.indet.}

MATERIAL. C. Africa, SW Rwanda, Nyungwa N.P., 18002000 m, 3-16.07.2014, leg. S. Kurbatov. E. Africa: Rwanda: SW Rwanda, Nyungwa N.P., Karamba trail, 1900 m, 4-16.07.2014, leg. S. Kurbatov; Nyungwa N.P., Kamiranzovu trail, 2000 m, 516.07.2014, leg. S. Kurbatov; S. Africa, SW Rwanda, Nyungwa N.P., Kamiranzovu trail, 1950 m, 10.07.2014, leg. S. Kurbatov; Rwanda, Nyungwa N.P., Umugote trail, 2400 m, 11.07.2014, leg. S. Kurbatov. 
REMARKS. Pubescence simple, pronotum weakly transverse, callosity large, occupying about $1 / 3$ length of side margin, very weakly set aside from the side of the edge, forms an obtuse angle without spike. The tip of the aedeagus is long, with corners outward, acicularly pointed at the very top. Parameres significantly shorter than apex of aedeagus, bottle-like, very wide basally and with long elongated neck, on top of paramere with 3 chaetae, its chaetae approximately equal in length, weakly curved, length of chaeta less than length of paramere.
This species is similar to several Central African species and it has not yet been possible to determine it.

\section{Micrambe zuluensis Lyubarsky, sp.n.}

Figs 3-5.

MATERIAL. Holotype: S. Africa: RSA, Kwa-Zulu Natal, Pietermaritzburg, Hilton, Malaise trap, 23.10-12.11.2003, leg. M. Mostovski, $\sigma^{7}$. Paratypes: S. Africa: RSA, Kwa-Zulu Natal, Pietermaritzburg, Hilton, Malaise trap, 27.0913.10.2003, leg. M. Mostovski, $8 \sigma^{\top} 41$; the same data,

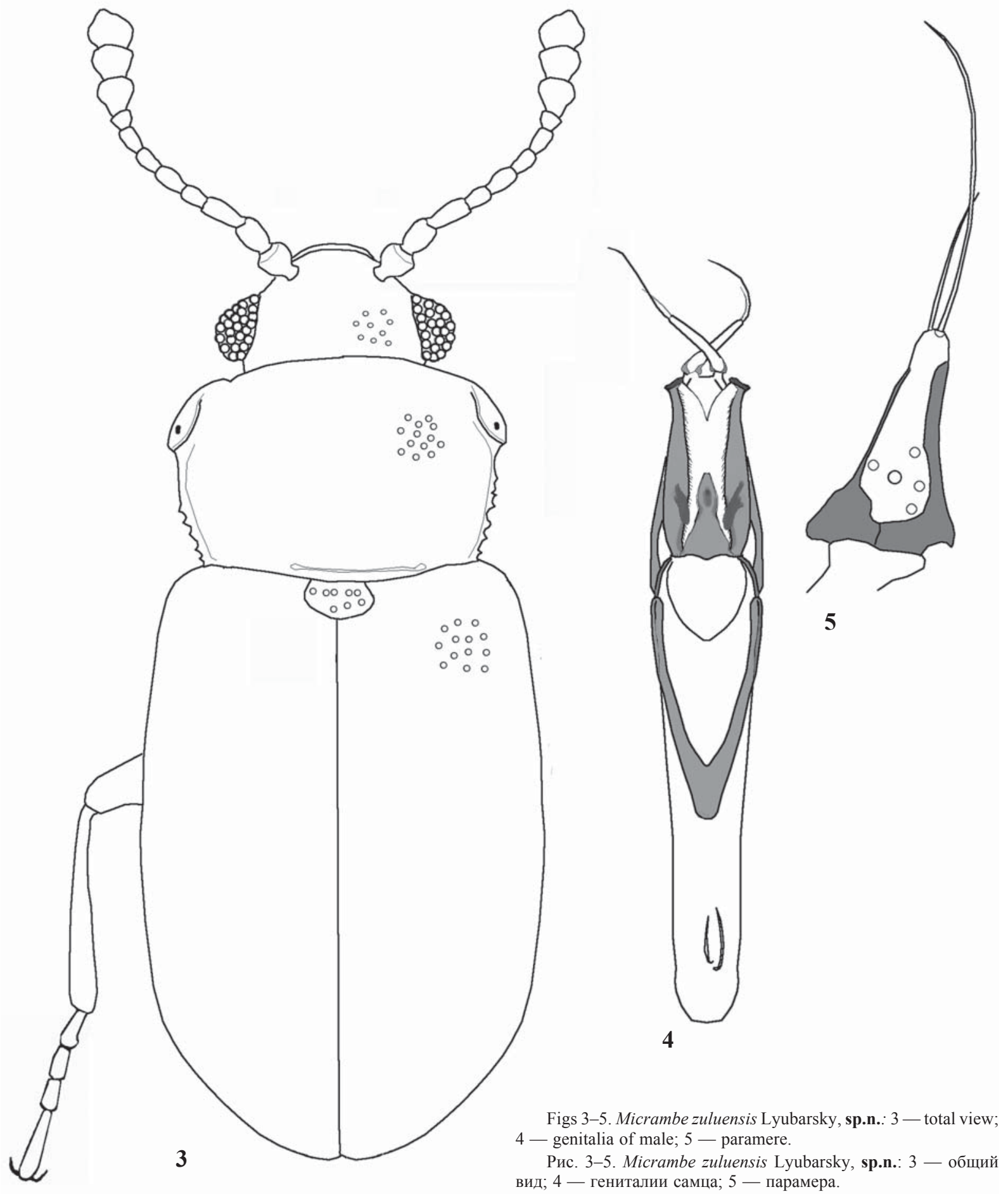


23.10-12.11.2003, leg. M. Mostovski, $3 \sigma^{\top} 2$; ; the same data, 13-23.11.2003, leg. M. Mostovski, $120^{7} 13$; ; the same data, 23.10-12.11.2003, leg. M. Mostovski, 260 16우 data, 24.11-09.12.2003, leg. M. Mostovski, 80 4; the same

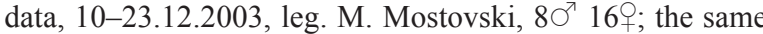
data, 24.12.2003-14.01.2004, leg. M. Mostovski, $80^{7} 20$; the same data, 15-26.01.2004, leg. M. Mostovski, $10^{\text {T } 1} 1$; the same data, 27.01-16.02.2004, leg. M. Mostovski, $3 \sigma^{7} 4$; the same data, 17-29.02.2004, leg. M. Mostovski, $10^{7} 3$; the same data, 29.02-13.03.2004, leg. M. Mostovski, 70 11 우

DESCRIPTION. Length: 1.4-1.7 mm. Body oval, moderately convex. Body colored from light yellowish brown to dark-brown with black longitudinal stripe along suture of elytra. Pubescence double $(\mathrm{L}=0.05-0.07 \mathrm{~mm})$. Metathoracic wings fully developed.

Head. Eyes normal $(\mathrm{L}=0.14 \mathrm{~mm})$, hemispheric, with facets smaller than the punctures of the head. Antennae long $(\mathrm{L}=0.65 \mathrm{~mm})$ surpassing the base of the pronotum. $3^{\text {th }}$ antennomere 1.6 times longer than the $4^{\text {th }} ; 3^{\text {th }}$ antennomere 1.6 times longer than the $5^{\text {th }} ; 6^{\text {th }}$ to $8^{\text {th }}$ equal and 1.2 times shorter than the $4^{\text {th }}$.

Pronotum (Fig. 2) strongly transverse (width/length ratio $=1.5-1.6)$. Anterior margin in regular curve. Large callosities $(1 / 3$ of the length of the side), hardly surpassing the lateral margin of the pronotum. Surface of callosity partly visible dorsally, pitted at centre and with a strong margin. It forms an obtuse angle posteriorly, without spike, and one of $30^{\circ}$ with the axis of the body. Lateral margin angular, sides almost parallel to the basal third and convergent toward the base. Lateral margin of pronotum with a callosity strongly prominent laterally, posteriorly lateral margin smooth, then forming three or four teeth with setae. Basal pits absent, basal groove present. Obtuse posterior angles. Basal edge with median lobes. Punctuation moderately strong; punctures (Fig. 2) separated by a distance smaller than their diameter.

Scutellum transverse, trapezoidal. Elytra 2.7 times longer than pronotum. Elytra 1.4 times longer than their combined width and 2.7 times longer than the pronotum. Punctures of same strength as those of pronotum and separated by a distance equal to their diameter. Tarsal formula $5-5-5$ in females and 5-5-4 in males.

Aedeagus (Fig. 3) expanded apically. This expansion presents a short hooked apex directed outwards. Apical part of aedeagus about 2 times as long as wide. On the sides of the apex of the aedeagus there are protrusions directed outward, similar to those of $M$. natalensis. Endophallic orifice visible in the base of the aedeagus.

Parameres (Fig. 3) elongated, triangular, with two apical seta and with scarce pores with and without small setae. Length of paramere three times as long as its width. Length of paramere about $1 / 3$ of length of the aedeagus. Apical setae of different lengths, longer seta longer than the length of the paramere. Length of the short seta from less than $1 / 2$ to about $2 / 3$ of the long seta.

BIOLOGY. Unknown.

DISTRIBUTION. South Africa: RSA: Kwazulu-Natal.

NAME DERIVATION. This species is named after the place of location, the province of Kwa-Zulu Natal.

REMARKS. In external characters it is very similar, for example, to M.natalensis. It differs in slightly smaller average sizes, somewhat more transverse pronotum, angular lateral edge of pronotum, and callosities hardly surpassing the lateral margin of the pronotum. This species was indicated in Lyubarsky [2011], but without a review of Micrambe species of S. Africa it was impossible to indicate the status of the species. In the works of Otero [Otero, 2005, 2012; Otero, Pereira 2017, 2018], the fauna of South Africa was well studied and it became possible to indicate the position of this species and its differences from related species.

The species belongs to the group with double pubescence of elytra. From the majority of the species of this group in South Africa, the new species can be distinguished by the presence of two setae of different lengths on the paramere; in the other species the setae are approximately equal in length.

The species of this group (double-pubescent) from South Africa can be identified by the following key:

1. Eyes normal, subhemispheric. Large callosity (length $=1 /$ 3 to $1 / 4$ of the length of the side) ............................... 2

- Eyes conical, protuberant. Callosity smaller (length $=1 / 4$ of the length of the side) and surpassing a little the lateral margin of the pronotum. Yellowish brown and sometimes with black spots in the elytra. Top of paramere with 2 setae of equal length. Setae on top of the paramere are less than the length of the paramere. Length of body $1.5-1.8 \mathrm{~mm}$ Micrambe plagiata Grouvelle, 1908

2. Tarsal formula 5-5-5 in both sexes ............................ 3

- Tarsal formula 5-5-5 in females and 5-5-4 in males ... 4

3. Pronotum transverse (width/length ratio $=1.7$ ). Sides of pronotum converge in a straight line from the callosity to the base. Large callosities (1/3 of the length of the side), surpassing the margin of the pronotum and separated from the disc by a depression. Reddish brown with a dark triangular band along the elytral suture. Top of paramere with 3 long setae of approximately equal length. Setae on top of the paramere are much longer than the length of the paramere. Length of body 1.9-2.1 mm

M. endroedyi Otero, 2005

- Pronotum small transverse (width/length ratio $=1.5$ ). Sides of pronotum parallel in the basal third, and from there, convergent toward the base. Elytra yellowish brown with dark spots expanding to the sides. Top of paramere with 2 long setae of approximately equal length. Setae on top of the paramere are much longer than the length of the paramere. Length of body 1.6-2 mm

M. hanstroemi (Bruce, 1957)

4. Large callosity surpassing scarcely the lateral margin of the pronotum. Sides of pronotum sinuated from the callosity toward the base

- Large callosity surpassing the lateral margin of the pronotum, separated from the disc of pronotum by a depression and surpassing strongly the lateral margin of the pronotum. Sides convergent or forming a curve from the callosity toward the base

5. Yellowish brown. Eyes normal, subhemispheric. Pronotum transverse (width/length ratio $=1.7$ ). Top of paramere with 2 setae of approximately equal length. Setae on top of the paramere are approximately equal to the length of paramere. The corners protruding to the sides at the top of the aedeagus are angular, not hook-shaped. Length of body $=1.7-1.8 \mathrm{~mm}$............... M. Mirta Grouvelle, 1908

- Reddish brown or yellowish brown; legs and antennae yellowish brown. Eyes large, hemispheric, prominent. 6

6. Body large (length $=2.1-2.3 \mathrm{~mm})$. Large callosity $(1 / 3$ of the length of the side). Sides of pronotum parallel in the anterior half and then convergent toward the base. Reddish brown. Top of paramere with 2 setae of equal length. Setae on top of the paramere are longer than length of paramere. The corners at the top of the aedeagus are not protruding to the sides, not hook-shaped.. M. simoni Grouvelle, 1895 
- Body smaller, less than $1.8 \mathrm{~mm}$........... 7

7. Pronotum transverse (width/length ratio $=1.8$ ), without a depression between the callosity and the disc of pronotum. Antennae with $3^{\text {rd }}$ antennomere only 1.2 times longer than $5^{\text {th }}$. Top of paramere with 2 setae of approximately equal length. Setae on top of the paramere are approximately equal to the length of paramere. The corners protruding to the sides at the top of the aedeagus are slightly angular, slightly hook-shaped. Length of body = 1.3-1.8 mm ............................ M. basuto (Bruce, 1957)

- Pronotum transverse (width/length ratio $=1.7$ ). Callosity separated from the disc by a depression. Antennae with $3^{\text {th }}$ antennomere 1.4 times longer than $5^{\text {th }}$. Top of paramere with 2 setae of approximately equal length. Setae on top of the paramere are shorter than paramere. The corners protruding to the sides at the top of the aedeagus are slightly angular, slightly hook-shaped. Length of body = 1.7-1.8 mm ...................... M. natalensis (Bruce, 1952)

8. Body larger $($ length $=1.7-1.8 \mathrm{~mm})$........................... 9

- Body smaller (length $=1.4-1.7 \mathrm{~mm}$ ). Pronotum strongly transverse (width/length ratio $=1.5-1.6)$. Body colored from light-brown to dark brown with longitudinal black strip along elytral suture. Eyes normal, subhemispheric. Lateral margin angular, sides almost parallel to the basal third and convergent toward the base. Top of paramere with 2 setae of different length. Longest apical seta longer than the length of the paramera. Length of the short seta less than half the length of the long seta. The corners protruding to the sides at the top of the aedeagus are angular, hook-shaped M. zuluensis sp.n.

9. Pronotum transverse (width/length ratio $=1.7-1.8$ ). Elytra reddish brown; head and pronotum dark brown. Eyes large, prominent. Sides of pronotum convergent in a straight line toward the base. Top of paramere with 2 setae of equal length. Setae longer than the length of the paramere. The corners protruding to the sides at the top of the aedeagus are not hook-shaped ....... M. nigrothoracica (Bruce, 1952)

- Pronotum transverse (width/length ratio $=1.6-1.7$ ). Large callosity not surpassing the lateral margin of the pronotum. Eyes large, hemispheric, and protuberant. Sides forming a slight angle in the centre. Yellowish brown or ferruginous brown. Top of paramere with 2 setae different in length. The longer seta is approximately equal to the length of the paramere, the smaller seta is $2 / 3$ of the length of the longer seta. The corners protruding to the sides at the top of the aedeagus are rounded, not hook-shaped. Body large, length of body $=2.0-2.1 \mathrm{~mm}$ M. peringueyi Grouvelle, 1908

\section{Henoticus C.G. Thompson, 1868 \\ Henoticus rotundatus Bruce, 1951}

Fig. 6.

MATERIAL. E. Africa, Rwanda: Nyungwe NP, 1800-2000 m, 3-16.07.2014, leg. Kurbatov S. (6 spec., Oج+); Nyungwe NP, Karamba trail, 1900 m, 4-16.07.2014, leg. Kurbatov S. (13 spec., O'o $)$ Nyungwe NP, Kamiranzovu trail, 2000 m, 5-16.07.2014, leg. Kurbatov S. (15 spec., $O^{7}+$ ); Nyungwe NP, 1950 m, Kamiranzovu trail bitting, 10.07.2014, leg. Kurbatov S. (1 spec.)

REMARKS. Tarsal formula of male 5-5-5, hind wing fully developed, with simple decumbent pubescence, eyes finely faceted. Length of body $1.6-1.8 \mathrm{~mm}$. The male genitalia are depicted in Bruce's description of the species, however, the detail of the image is insufficient. Aedeagus and paramere of $H$. rotundatus depictured in Fig. 6.

DISTRIBUTION. C.Africa: Burundi (Gitebe), DR Congo, Uganda, Rwanda. New for Rwanda.

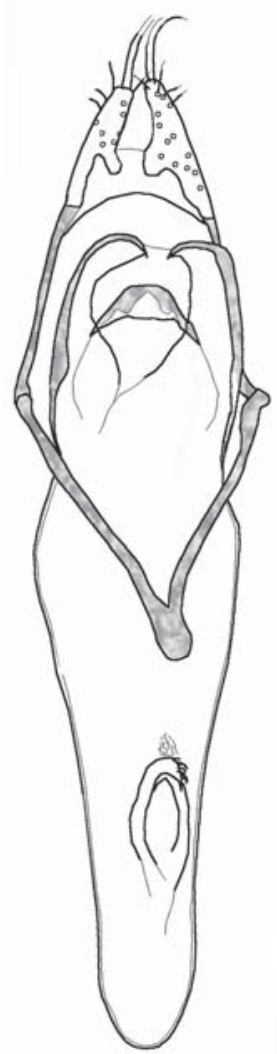

Fig. 6. Henoticus rotundatus Bruce, genitalia of male.

Рис. 6. Henoticus rotundatus Bruce, гениталии самца

Henoticus ?proprius Grouvelle, 1899

MATERIAL. S. Africa: RSA, Natal Impendle, Nhlosana farm Cattle site, 23.11.1993, pitfall traps, leg. J. Kotze $10^{2}$.

DISTRIBUTION. S.Africa: RSA: Natal.

REMARKS. Tarsal formula of male 554, hind wing absent. Length of body $1.7 \mathrm{~mm}$.

Cryptophagus Herbst, 1792

Cryptophagus laticollis Lucas, 1846

MATERIAL. S. Africa: RSA, Kwa-Zulu Natal, Pietermaritzburg, Hilton, Malaise trap, 27.09-13.10.2003, leg. M. Mostovski, 3 spec.; the same data, 23.10-12.11.2003, leg. M. Mostovski, 2 spec.

DISTRIBUTION. Cosmopolitan distribution, synanthropic species.

Atomaria Stephens, 1829

Atomaria lewisi Reitter, 1877

MATERIAL. La Reunion, 974, Entre-Deux, Bras lng, Piege luminieux, 9.01.2013 coll. J. Poussereau, (1 spec.). S.Africa: RSA, Kwa-Zulu Natal, Pietermaritzburg, Hilton, Malaise trap, 24.12.0314.01.2004, leg. M. Mostovski (4 spec.); the same data, 23.1024.11.2003 (6 spec.); the same data, 17-29.02.2004, leg. M. Mostovski (1 spec.), the same data, 10-23.12.2003 (1 spec.); the same data, 27.09-13.10.2003, leg. M. Mostovski (15 spec.); the same data, 24.11-09.12.2003 (1 spec.)

DISTRIBUTION. Cosmopolitan distribution, synanthropic species.

Atomaria marshalli Johnson, 1968

MATERIAL. S. Africa: RSA, Kwa-Zulu Natal, Pietermaritzburg, Hilton, Malaise trap, 27.09-13.10.2003, leg. M. Mostovski, 4 spec. 
DISTRIBUTION. S. Africa: Estcourt, Cape Prov. [Johnson, 1968, 1970].

Curelius Casey, 1900

Curelius japonicus (Reitter, 1878)

MATERIAL. S. Africa: RSA, Kwa-Zulu Natal, Pietermaritzburg, Hilton, Malaise trap, 13-23.11.2003, leg. M. Mostovski, 1 spec.; the same data, 24.12.2003-14.01.2004, leg. M. Mostovski, 4 spec.; the same data, 15-26.01.2004, leg. M. Mostovski, 3 spec.; the same data, 27.01-16.02.2004, leg. M. Mostovski, 1 spec.; the same data, 17-29.02.2004, leg. M. Mostovski, 8 spec.; the same data, 29.0213.03.2004, leg. M. Mostovski, 4 spec.

DISTRIBUTION. Africa: Cameroon, Guinea, Namibia, Nigeria, RSA, Sudan, Tanzania, Togo, Zambia, Zimbabwe [Esser, 2017]. Curelius japonicus widespread in tropical and subtropical areas of all zoogeographic regions.

Curelius jaegeri Esser, 2017

MATERIAL. S. Africa: RSA, Kwa-Zulu Natal, Pietermaritzburg, Hilton, Malaise trap, 15-26.01.2004, leg. M. Mostovski, 1 spec.; S Africa, Kwa-Zulu Natal, Pietermaritzburg, Hilton, Malaise trap, 17-29.02.2004, leg. M. Mostovski, 1 spec.; the same data, 24.12.2003-14.01.2004, leg. M. Mostovski, 2 spec.

REMARKS. Esser [2017] is described of this species from Namibia and RSA.

DISTRIBUTION. S. Africa: Namibia, RSA.

Acknowledgments. The work has been supported by the grant AAAA-A16-116021660077-3.

\section{References}

Esser J. 2017. On Curelius CASEY, 1900 and Ephistemus STEPHENS, 1829 (Coleoptera, Cryptophagidae) from the Afrotropical Region // Linzer biol. Beitr. Vol.49. No.2. P.1139-1145.

Johnson C. 1968. Some interesting species of Atomaria Stephens (Col., Cryptophagidae) in the British Museum // Entomologist. Vol.101. P.228-231.

Johnson C. 1970. Coleoptera: Cryptophagidae: Atomariinae // South African animal life. Results of the Lund University. Expedition in 1950-1951. Vol.14. P.228-229.

Lyubarsky G.Yu. 2011. Cryptophagidae (Coleoptera) of the KwaZulu Natal (South Africa)// Russian Entomological Journal. Vol.20. No.1. P.65-66.

Lyubarsky G. 2013. New species of Cryptophagidae and Erotylidae (Coleoptera) from the Mascarene Islands // Latvijas Entomologs. Vol.52. P.58-67.

Lyubarsky G. 2015. New genus Microticus from Upper Cretaceous of Taymyr (Coleoptera: Cryptophagidae), oldest silken fungus beetle with sexually dimorphic tarsal formula // Russian Entomological Journal. Vol.24. No.1. P.61-66.

Otero J.C. 2005. A new south african species of Micrambe C.G. Thomson, 1863 (Coleoptera: Cryptophagidae), including new synonymies of Micrambe species // Elytron. Vol.19. P.83-87

Otero J.C. 2012. The species of the genus Micrambe Thomson 1863, from South Africa (Coleoptera: Cryptophagidae) // Ann. soc. entomol. Fr. (n.s.). Vol.48. Nos3-4. P.407-438.

Otero J.C., Pereira J.M. 2017. Records of the genus Micrambe Thomson, 1863 (Coleoptera, Cryptophagidae) from Madagascar and Réunion Island // African Invertebrates. Vol.58. No.1. P.49-64.

Otero J.C., Pereira J.M. 2018. On a new species of Micrambe from Africa (Coleoptera, Cryptophagidae) // ZooKeys. Vol.748. 47-56.

Otero J.C., Pereira J.M. 2019. Neomicrambe subgen. nov. of Micrambe Thomson, 1863 (Coleoptera: Cryptophagidae) from East Africa // Zootaxa. Vol.4674. No.1. P.47-67. 